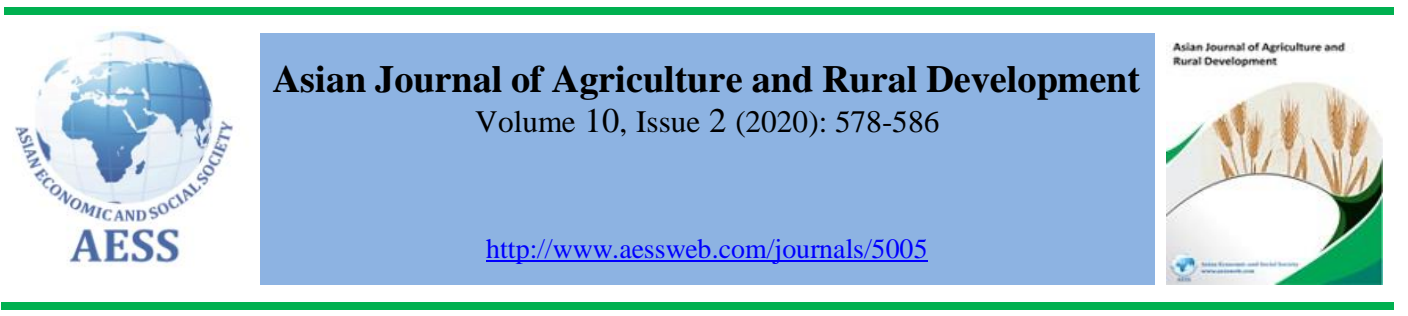

\title{
FORECASTING IMPORT DEMAND OF TABLE GRAPES: EMPIRICAL EVIDENCE FROM THAILAND
}

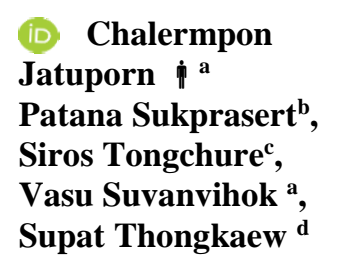

\section{ARTICLE HISTORY:}

Received: $27-$ Mar-2020

Accepted: 04-Jun-2020

Online Available: $20-\mathrm{Jul}-$ 2020

\section{Keywords:}

Box-Jenkins,

Seasonal forecasting,

Table grape a School of Economics, Sukhothai Thammathirat Open University, Thailand

${ }^{\mathrm{b}}$ Faculty of Agriculture, Kasetsart University, Thailand

${ }^{c}$ Faculty of Agriculture and Life Sciences, Chandrakasem Ratchabhat University, Thailand

${ }^{\mathrm{d}}$ Crop Integration Business, C. P. Group, Thailand

\ chalermpon.jat@stou.ac.th; jatuporn.stou@gmail.com (Corresponding author)

ABSTRACT
The purpose of this study is to forecast the import demand of table
grapes of Thailand using monthly time series from January 2007 to
April 2020. The ADF unit root test is used for stationarity checking,
and seasonal autoregressive integrated moving average (SARIMA) is
applied to forecast the import demand of table grapes. The results
revealed that the integration of time series was in the first difference
for non-seasonal and seasonal order. The best-fitted forecasting model
was SARIMA $(1,1,3)(2,1,0)_{12}$. The forecasted period for the next eight
months showed the import demand of table grapes of Thailand that is
slightly decreased by an average of 11.398 percent, with overall
expected to decrease by an average of 15.218 percent in 2020 .

\section{Contribution/ Originality}

The forecasting of table grapes in Thailand is less studied in the literature. Seasonal Autoregressive Integrated Moving Average model is appropriate to forecast the time series composed of trend and seasonal elements that is applied in this study.

DOI: 10.18488 /journal.ajard.2020.102.578.586

ISSN(P): 2304-1455/ ISSN(E): 2224-4433

How to cite: Chalermpon Jatuporn, Patana Sukprasert, Siros Tongchure, Vasu Suvanvihok and Supat Thongkaew (2020). Forecasting import demand of table grapes: Empirical evidence from Thailand. Asian Journal of Agriculture and Rural Development, 10(2), 578-586. 


\section{INTRODUCTION}

Grapes have long been an important fruit for the world's consumers. It is an economic crop that generates income for farmers. Grapes can be eaten fresh or processed into various products. It contains medicinal properties to prevent disease and can be used as a component in cosmetic products, and so on. It has been assumed that grapes were imported to Thailand and planted since the reign of King Rama V, in which grape varieties started to have been developed. The table grape varieties, consisting of White Malaga, Black Opal, and Cardinal, are largely planted and consumed in Thailand. At present, there have been successive demand for grapes, but the production is not sufficient to meet domestic consumption. According to the 2018's statistics, Thailand has imported more than 118,316 tons of table grapes from foreign countries, equivalent to 4,854 million baht or accounted for 14.41 percent compared to all imported value of fruits and products, while Thailand's grape production capacity can supply only 14,305 tons. The top exporters of table grapes to Thailand are China, Australia, Peru, the United States, and India, respectively (Department of Agricultural Extension 2019; Office of the Permanent Secretary 2019; Office of Agricultural Economics, 2020). This data shows that there is still a large amount of excess demand occurring within the country each year. The main reasons that Thai farmers do not grow grapes or with low yield are attributed to the highly paid investment and relatively high production cost, such as a plastic house, net house coverings, labor wages, fertilizers, pesticides, pest control costs, maintenance costs, insufficient knowledge and sources of funds. As such, these hinder small farmers from growing grapes. The grape planting, compared to other crops, has a high risk due to diseases, pests, as well as rising climate change that easily causes harm. To circumvent these problems needs a lot of capital; however, grapes' price that farmers sell has been unstable. Besides, the import of grapes from abroad is also at a lower cost than domestic; thus, some people import table grapes from foreign countries instead of investing in domestic planting.

Forecasting import demand for table grapes of Thailand is an important plan in dealing with domestic consumption needs. According to a review of documents and related research, few studies have been published which examine these issues. For example, Lertsivanont and Boonserm (2014) forecasted the import demand of table grapes from China using quarterly time series over the 4th quarter of 2003 to the 4th quarter of 2012 with a total of 40 samples which were analyzed using the vector autoregressive model (VAR) followed by the forward data forecast until 2015. The results of this study show that per capita income determined the import demand of grapes from China. In other words, if people have more income, the import demand for grapes from China will be more likely to increase until 2015. However, studies related to forecasting of agricultural production by using time series analysis have a large number of case studies, such as Jatuporn and Sukprasert (2016) developed the forecasting models of rubber production and export quantity of Thailand. The statistical methodology consists of three techniques, namely, a regression model with seasonal dummy and time trend, Box-Jenkins concepts, and exponential smoothing. To compare the efficiency of the forecasting models, Jatuporn and Sukprasert (2016) used the root mean square error (RMSE) to determine the best-fitted model and then forecasted the data forward for 16 months. The empirical results found that the regression with seasonal dummy and time trend is the best-fitted model based on the lowest value of the RMSE benchmark.

Moreover, Keerativibool (2014) forecasted the export value of Thai Jasmine rice using monthly time series, starting from June 2002 to July 2013, and a total of 134 samples were collected. The study considered three forecasting models by Box-Jenkins, Winters additive exponential smoothing, and combined forecasting method. The study used the mean absolute percentage error (MAPE) as a criterion for comparing the accuracy of the forecasts. The results indicated that the combined forecasting method is the most accurate method that provides the lowest value of the MAPE statistics. Likewise, Masood et al. (2018) used time series models to predict wheat production in Pakistan based on linear, quadratic, exponential, S-Curve, double exponential smoothing, single exponential smoothing, moving average, and ARIMA. The conclusion of 
Masood et al. (2018) showed that $\operatorname{ARIMA}(2,1,2)$ was selected as the best forecasting model to predict wheat production in Pakistan. Numerous studies employed the relationship between actual and forecasted value using the correlation coefficient to explain forecasting model efficiency [see, for instance, Lim et al. (2009a), Chang et al. (2009), and Kulthatpong et al. (2019)].

The objective of this study is to forecast the import demand of table grapes of Thailand using the Box-Jenkins procedure. The Akaike criterion and Schwarz criterion are utilized to select the fitted model of ARIMA(p,d,q), as of Kuo et al. (2008), Lim et al. (2009b), and Saengwong et al. (2012). In the next section, the research methodology consisting of data, variables, and forecasting model, is explained. Then, the results of the empirical study and conclusions as proposed policy suggestions are discussed.

\section{METHODOLOGY}

The data of this study is the monthly time series, from January 2007 to April 2020, a total of 160 samples are gathered from the Information and Communication Technology Center, Office of the Permanent Secretary, Ministry of Commerce with cooperation from the Customs Department. For the variable $\left(\mathrm{Q}_{\mathrm{GRAPE}}\right)$, the number of table grape imports is used with the harmonize code of 08061000 .

The analysis of time series techniques requires the testing of the properties of the time series because erroneous results would probably arise if the data used in the analysis is not stationary (Non-stationary process). The problem is called a spurious relationship, which results from the influence of time distorting the outcomes (Granger and Newbold, 1974). The checking can be examined by various means, such as considering the line graph, correlogram diagram, or statistical testing by using the unit root method. However, analyzing the time series properties of this study using the Augmented Dickey-Fuller (ADF) unit root of Dickey and Fuller $(1979,1981)$ has been performed in testing the stationarity of the Q QRAPE which can be displayed as the equation (1), (2) and (3), respectively.

$$
\begin{aligned}
& \Delta \mathrm{Q}_{\mathrm{GRAPE}, \mathrm{t}}=\beta_{1} \mathrm{Q}_{\mathrm{GRAPE}, \mathrm{t}-1}+\sum_{\mathrm{i}=1}^{\mathrm{p}} \beta_{2} \Delta \mathrm{Q}_{\mathrm{GRAPE}, \mathrm{t}-\mathrm{i}}+\varepsilon_{\mathrm{t}} \\
& \Delta \mathrm{Q}_{\mathrm{GRAPE}, \mathrm{t}}=\alpha_{0}+\beta_{1} \mathrm{Q}_{\mathrm{GRAPE}, \mathrm{t}-1}+\sum_{\mathrm{i}=1}^{\mathrm{p}} \beta_{2} \Delta \mathrm{Q}_{\mathrm{GRAPE}, \mathrm{t}-\mathrm{i}}+\varepsilon_{\mathrm{t}} \\
& \Delta \mathrm{Q}_{\mathrm{GRAPE}, \mathrm{t}}=\alpha_{0}+\delta \mathrm{T}+\beta_{1} \mathrm{Q}_{\mathrm{GRAPE}, \mathrm{t}-1}+\sum_{\mathrm{i}=1}^{\mathrm{p}} \beta_{2} \Delta \mathrm{Q}_{\mathrm{GRAPE}, \mathrm{t}-\mathrm{i}}+\varepsilon_{\mathrm{t}}
\end{aligned}
$$

Where $\alpha, \delta$ and $\beta$ are identified as the parameters to be estimated, $\Delta$ is the differencing order, $T$ is the time trend, $t$ is the time period, $\varepsilon$ is the error term, and $p$ is the optimal lag selection of AR based on the lowest value of the Schwarz criterion.

The forecasting models employed the time series method of Box et al. (1994) or autoregressive integrated moving average (ARIMA), which is a widely common model for analyzing and forecasting time series data. The method considered the behavior of the data itself in the past to determine the current pattern and predict future information. The model is divided into three components: $\operatorname{AR}(p), I(d)$, and MA(q) or $\operatorname{ARIMA}(p, d, q)$. The forecasting process using Box-Jenkins procedure can be divided into four steps (Gujarati and Porter, 2009): (1) identifying the 
$\operatorname{ARIMA}(\mathrm{p}, \mathrm{d}, \mathrm{q})$ by considering I(d) with the ADF unit root and considering $\operatorname{AR}(\mathrm{p})$ and MA(q) with the correlogram diagram, respectively, (2) estimating the parameters with maximum likelihood (ML), (3) checking for the serial correlation with Ljung-Box Q statistics ( $\left.\mathrm{Q}_{\mathrm{LB}}\right)$, and (4) forecasting forward for eight months till to December 2020. However, if the ARIMA(p,d,q) is found more than one model. It needs to be selected for the most fitted model using the lowest value of the Akaike criterion (AC) and Schwarz criterion (SC). ARIMA(p,d,q) was configured by the equation (4).

$\Delta \mathrm{Q}_{\mathrm{GRAPE}, \mathrm{t}}=\alpha_{0}+\sum_{\mathrm{i}=1}^{\mathrm{p}} \phi_{\mathrm{i}} \Delta \mathrm{Q}_{\mathrm{GRAPE}, \mathrm{t}-\mathrm{i}}+\sum_{\mathrm{j}=1}^{\mathrm{q}} \theta_{\mathrm{j}} \varepsilon_{\mathrm{t}-\mathrm{j}}+\varepsilon_{\mathrm{t}}$

Where $\mathrm{p}$ is specified as the past period of $\mathrm{Q}_{\mathrm{GRAPE}}, \mathrm{q}$ is the preceding period of $\varepsilon$, and $\phi$ and $\theta$ are the parameters to be estimated of $\operatorname{AR}(p)$ and $M A(q)$, respectively.

However, the ARIMA model in equation (4) is fitted for a time series without seasonality. In other words, $\operatorname{ARIMA}(\mathrm{p}, \mathrm{d}, \mathrm{q})$ is a model to predict time series that contains only the elements of a time trend. According to the variable ( $\left.\mathrm{Q}_{\mathrm{GRAPE}}\right)$, it contains the influence of time trend and seasonal components. Therefore, Box et al. (1994) proposed the seasonal ARIMA model or $\operatorname{SARIMA}(\mathrm{p}, \mathrm{d}, \mathrm{q})(\mathrm{P}, \mathrm{D}, \mathrm{Q}) \mathrm{s}$ to predict the time series with time trend and seasonal elements by including additional $\mathrm{P}, \mathrm{D}, \mathrm{Q}$ and $\mathrm{s}$ as $\mathrm{SAR}(\mathrm{P})$, seasonal order of integration or $\mathrm{I}(\mathrm{D}), \mathrm{SMA}(\mathrm{Q})$ and seasonal frequency (s), respectively. SARIMA(p,d,q)(P,D,Q)s can be configured by the Equation (5).

$\phi_{\mathrm{p}}(\mathrm{B}) \Phi_{\mathrm{P}}\left(\mathrm{B}^{\mathrm{s}}\right)(1-\mathrm{B})^{\mathrm{d}}\left(1-\mathrm{B}^{\mathrm{s}}\right)^{\mathrm{D}} \mathrm{Q}_{\mathrm{GRAPE}, \mathrm{t}}=\theta_{\mathrm{q}}(\mathrm{B}) \Theta_{\mathrm{Q}}\left(\mathrm{B}^{\mathrm{s}}\right) \varepsilon_{\mathrm{t}}$

Where $\phi_{\mathrm{p}}(\mathrm{B})$ and $\theta_{\mathrm{q}}(\mathrm{B})$ are structured with no seasonal components of $\operatorname{AR}(\mathrm{p})$ and $\mathrm{MA}(\mathrm{q})$ respectively, while $\Phi_{\mathrm{P}}(\mathrm{Bs})$ and $\Theta_{\mathrm{Q}}(\mathrm{Bs})$ are structures that contain seasonal components of $\mathrm{SAR}(\mathrm{P})$ and SMA(Q), respectively (Makridakis et al., 1998; Jatuporn et al., 2016).

\section{RESULTS AND DISCUSSION}

In time series analysis, it is necessary to examine the properties of the time series to prevent the spurious relationship because such problems will skew the results from the actual values. Therefore, in the process of testing the time series of $\mathrm{Q}_{\mathrm{GRAPE}}$, the test for stationarity by Dickey and Fuller $(1979,1981)$, the ADF unit root method was used. The null hypothesis $\left(\mathrm{H}_{0}\right)$ is that the variable is a non-stationary time series. If the output does not have a statistical significance level of 0.05 , that is, the time series is non-stationarity, we have to find the first differencing order of the data and then retake the test until the data is stationarity. ${ }^{1}$

Testing for stationarity by using the ADF unit root is shown in Table 1 . The model is based under three conditions: (1) the ADF model without constant $(\alpha)$ and time trend (T), (2) the ADF model with constant $(\alpha)$, and (3) the ADF model with constant $(\alpha)$ and time trend (T). The results showed that the variable $\left(\mathrm{Q}_{\mathrm{GRAPE}}\right)$ provided the t-ratio equal to (1.063), (-1.074), and (-1.605), respectively. The results of the analysis could not reject the null hypothesis of non-stationarity at a significance level of 0.05. It can be concluded that the Q QRAPE time series is not stationarity at the normal level stage. Then, the data is converted to the first difference and then tested again, which specified the statistics of the t-ratio equal to (-12.097), (-12.311), and (-12.292), respectively. The results of the analysis rejected the null hypothesis at a significance level of 0.01 , that is, the $\mathrm{Q}_{\mathrm{GRAPE}}$ time series is stationarity with the order of integration or $\mathrm{I}(\mathrm{d})$ is equal to $\mathrm{I}(1)$. However, the $\mathrm{Q}_{\mathrm{GRAPE}}$ time series contains seasonal components with the frequency of the seasonality (s) equal to 12 . Therefore, there is a need to try out stationarity of the seasonal or $\mathrm{I}(\mathrm{D})$ as well. Also, the results of the analysis in

${ }^{1}$ The data was analyzed using the Gretl program (Gnu Regression, Econometrics, and Time-series Library) 
Table 1 showed that $\mathrm{I}(\mathrm{D})$ of the $\mathrm{Q}_{\mathrm{GRAPE}}$ time series ranked the seasonal stationarity as the first seasonal difference with rejected the null hypothesis at a significance level of 0.01 , that is, I(D) is equal to $\mathrm{I}(1)$ as specified the statistics of the t-ratio equal to $(-5.254),(-5.230)$ and $(-5.207)$, respectively.

Table 1: The results of the ADF unit root test

\begin{tabular}{lcccccc}
\hline \multirow{2}{*}{ Model } & \multicolumn{2}{c}{ Non-seasonal I(0) } & \multicolumn{2}{c}{ Non-seasonal I(1) } & \multicolumn{2}{c}{ Seasonal I(1) } \\
& t-ratio & p-value & t-ratio & p-value & t-ratio & p-value \\
\hline ADF without $\alpha+\mathrm{T}$ & & & & & & \\
$\quad \begin{array}{l}\text { Q } \\
\text { GRAPE }\end{array}$ & 1.063 & 0.925 & -12.097 & $<0.001$ & -5.254 & $<0.001$ \\
$\begin{array}{l}\text { ADF with } \alpha \\
\quad \begin{array}{l}\text { Q } \\
\text { GRAPE }\end{array}\end{array}$ & -1.074 & 0.728 & -12.311 & $<0.001$ & -5.230 & $<0.001$ \\
$\begin{array}{l}\text { ADF with } \alpha+\mathrm{T} \\
\quad \text { Q }\end{array}$ & -1.605 & 0.791 & -12.292 & $<0.001$ & -5.207 & $<0.001$ \\
\hline
\end{tabular}

ADF without $\alpha+\mathrm{T}$, ADF with $\alpha$, and ADF with $\alpha+\mathrm{T}$ refer to the unit root models from equation (1), (2), and (3), respectively.

$\mathrm{I}(0), \mathrm{I}(1)$, and I(D) refer to the order of integration of level stage for $\mathrm{I}(0)$, the first difference for $\mathrm{I}(1)$, and the first seasonal difference for $\mathrm{I}(\mathrm{D})$, respectively

The results of the stationary testing of the $\mathrm{Q}_{\mathrm{GRAPE}}$ time series can be concluded that the stationary rating $I(d)$ is equal to $I(1)$, the stationarity of the seasonal $I(D)$ is equal to $I(1)$ and the frequency of seasonality (s) is equal to 12 ; thus the model of $\operatorname{SARIMA}(\mathrm{p}, \mathrm{d}, \mathrm{q})(\mathrm{P}, \mathrm{D}, \mathrm{Q}) \mathrm{s}$ primarily represents $\operatorname{SARIMA}(\mathrm{p}, 1, \mathrm{q})(\mathrm{P}, 1, \mathrm{Q})_{12}$. Then, the forecasting model was determined by considering the correlogram diagram for decision making, and configured by the parameters with the next highest probability method.

Table 2 presents the results of the parameter estimation using ML estimator of six models of SARIMA(p,d,q)(P,D,Q)s, which are fitted for forecasting based on the coefficients $\phi, \theta, \Phi$ and $\Theta$ at a significance level of 0.05 . All the models in Table 2 were no serial correlation problem because the outputs from the $\mathrm{Q}_{\mathrm{LB}}$ statistics could not reject the null hypothesis of the model without serial correlation. Finally, SARIMA $(1,1,3)(2,1,0)_{12}$ is selected as the appropriate forecasting model because it shows the lowest value of the AC and SC statistics as (2744.625) and (2762.568), respectively.

The forecasting results for import demand of table grapes of Thailand ( $\mathrm{Q}_{\mathrm{GRAPE}}$ ) using the model of SARIMA $(1,1,3)(2,1,0)_{12}$ found that the number of table grapes consumed in Thailand during the remaining eight months of the year 2020 is $98,863.572$ tons, which decreased by 11.398 percent when compared to the same period of the previous year 2019 . 
Table 2: The results of SARIMA(p,d,q)(P,D,Q)s

\begin{tabular}{|c|c|c|c|c|c|c|}
\hline \multirow{2}{*}{ Variable } & \multicolumn{6}{|c|}{ Coefficients of SARIMA $(p, d, q)(P, D, Q) s$} \\
\hline & $(1,1,3)(2,1,0)_{12}$ & $(2,1,3)(0,1,1)_{12}$ & $(2,1,3)(1,1,0)_{12}$ & $(2,1,9)(0,1,1)_{12}$ & $(9,1,3)(0,1,1)_{12}$ & $(12,1,3)(0,1,0)_{12}$ \\
\hline$\phi_{1}$ & $-0.302 *$ & & & & & \\
\hline$\phi_{2}$ & & $-0.197 *$ & $-0.231 *$ & $-0.168 *$ & $-0.177 *$ & $-0.191 *$ \\
\hline$\phi_{9}$ & & & & & $0.171 *$ & \\
\hline$\phi_{12}$ & & & & & & $-0.509 *$ \\
\hline$\theta_{1}$ & & $-0.347 *$ & $-0.371 *$ & $-0.389 *$ & $-0.383 *$ & $-0.396^{*}$ \\
\hline$\theta_{2}$ & $-0.333^{*}$ & & & & & \\
\hline$\theta_{3}$ & -0.447 & $-0.514^{*}$ & $-0.489 *$ & $-0.469^{*}$ & $-0.506^{*}$ & $-0.482 *$ \\
\hline$\theta_{9}$ & & & & $0.261^{*}$ & & \\
\hline$\Phi_{1}$ & $-0.763^{*}$ & & $-0.525^{*}$ & & & \\
\hline$\Phi_{2}$ & $-0.381 *$ & & & & & \\
\hline$\Theta_{1}$ & & $-0.643^{*}$ & & $-0.698 *$ & $-0.627 *$ & \\
\hline $\mathrm{Q}_{6}(\mathrm{p}$-value $)$ & $2.582(0.108)$ & $1.651(0.438)$ & $0.719(0.698)$ & $1.750(0.186)$ & $1.530(0.216)$ & $1.277(0.528)$ \\
\hline $\mathrm{Q}_{12}$ (p-value) & $9.958(0.191)$ & $11.328(0.184)$ & $14.157(0.078)$ & $9.068(0.248)$ & $8.303(0.307)$ & $15.066(0.058)$ \\
\hline $\mathrm{AC}$ & 2744.625 & 2748.069 & 2760.822 & 2744.802 & 2746.142 & 2760.596 \\
\hline $\mathrm{SC}$ & 2762.568 & 2763.021 & 2775.774 & 2762.745 & 2764.085 & 2775.548 \\
\hline
\end{tabular}

* denotes the statistical significance at $5 \%$ level.

QLB denotes the Ljung-Box Q statistics.

$\mathrm{AC}$ and $\mathrm{SC}$ denote the Akaike criterion and Schwarz criterion

$\phi, \theta, \Phi$, and $\Theta$ denotes the estimated parameters of $\operatorname{AR}(\mathrm{p}), \operatorname{MA}(\mathrm{q}), \operatorname{SAR}(\mathrm{P})$ and $\mathrm{SMA}(\mathrm{Q})$, respectively. 


\section{CONCLUDING REMARKS}

The purpose of this study is to forecast the import demand of table grapes of Thailand using the Box-Jenkins procedure. The analysis of the fitting forecasting model is performed by considering the lowest value of the AC and SC statistics, which is $\operatorname{SARIMA}(1,1,3)(2,1,0)_{12}$ and then predicting for the next eight months to see the trend of demand for table grapes consumed in Thailand. Furthermore, the efficiency of the forecasting model SARIMA(p,d,q)(P,D,Q)s, according to the study of Lim et al. (2009a), Chang et al. (2009) and Kulthatpong et al. (2019), was analyzed from the correlation coefficient that can explain the relationship between the actual value and forecasted value. It was found that the forecasting model of $\operatorname{SARIMA}(1,1,3)(2,1,0)_{12}$, which was established, provides the forecasted value when compared to the actual value with the correlation coefficient equal to 0.925 . This result suggests that the forecasting model can explain the correlation with the actual value ( $\mathrm{Q}_{\mathrm{GRAPE}}$ ) up to 92.580 percent. The findings of this empirical study present that the import demand of table grapes to Thailand from January to April 2020 based on actual value decreased by 30.299 percent as well as the whole year of 2020 is expected to decrease by 15.218 percent when compared to the same period of the previous year 2019. The dramatic decline in the import quantity of table grapes is the result of a Coronavirus disease (COVID-19) that has decreased domestic demand.

The import of table grapes to Thailand has still massively existed. The main reason is that the production is insufficient for domestic consumption. The investment of farmers for grape plantation involves high production costs and intricate management. Given the climate change, insect, and pest epidemic, farmers who need to grow grapes in the plastic house with net house coverings require more efficient production control, which causes more production costs. Following the study of Promchon et al. (2018), it was found that many farmers stopped planting grapes and grew other crops instead. At present, the price that farmers sell does not encourage farmers to grow grapes due to its high risks. Based on empirical data, it was found that the import price of table grapes during the past five years $(2015$ - 2019) is likely to decrease by an average of 2.866 percent per year. Moreover, the import price of table grapes from abroad has lower than the domestic price of $7.971 \%$ in 2018 . Therefore, entrepreneurs tend to import table grape from abroad to meet the needs of domestic consumption.

The plan of planting grapes in response to domestic demand must be aligned with the imported quantity; otherwise, it will affect the price at which farmers could sell and their occupational future. The study suggests that the effective production system must be improved in some aspects, especially the planting of grapes in the plastic house with net house coverings that help produce higher quality products and provides a reasonable price with good quality. Besides, growing grapes in the plastic house with net house coverings can also reduce losses due to diseases, pests, climate fluctuations, and so on. However, the investment in building a plastic house with net coverings to grow grapes is relatively high. If the government sector comes to assist with low-interest loans or has crop insurance programs for grape growers, it will help them to bear a risk of growing grapes. Moreover, the government should assist in the development of grape production technology, especially the development of grape varieties to withstand diseases and pests or tolerate climate fluctuations. For future research recommendations, there should be more studies analyzing the efficiency of grape production and, cost and benefit of grape plantation with technologies to find the ways to produce the most efficient and the optimal cost with good product quality. Finally, risk management of grape plantation should, therefore, be performed to support farmers to grow the table grapes. 
Funding: This study received no specific financial support.

Competing Interests: The authors declare that they have no competing interests.

Contributors/Acknowledgement: All authors participated equally in designing and estimation of current research.

Views and opinions expressed in this study are the views and opinions of the authors, Asian Journal of Agriculture and Rural Development shall not be responsible or answerable for any loss, damage or liability, etc. caused in relation to/arising out of the use of the content.

\section{References}

Box, G. E. P., Jenkins, G. M., \& Reinsel, G. C. (1994). Time series analysis: Forecasting and control. ( $3^{\text {rd }}$ edition). New Jersey: Englewood Cliffs Prentice-Hall.

Chang, C. L., Sriboonchitta, S., \& Wiboonpongse, A. (2009). Modelling and forecasting tourism from East Asia to Thailand under temporal and spatial aggregation. Mathematics and Computers in Simulation, 79(5), 1730-1744. doi.org/10.1016/j.matcom.2008.09.006.

Department of Agricultural Extension (2019). Crop overview of Thailand 2018/19. Department of Agricultural Extension, Ministry of Agriculture and Cooperatives. Bangkok: Thailand.

Dickey, D., \& Fuller, W. A. (1979). Distributions of the estimators for autoregressive time series with a unit root. Journal of the American Statistical Association, 74(366), 427-431. doi.org/10.1080/01621459.1979.10482531.

Dickey, D., \& Fuller, W. A. (1981). Likelihood ratio statistics for autoregressive time series with a unit root. Econometrica, 49(4), 1057-1072. doi.org/10.2307/1912517.

Granger, C. W. J., \& Newbold, P. (1974). Spurious regressions in econometrics. Journal of Econometrics, 2(2), 111-120.

Gujarati, D. N., \& Porter, D. C. (2009). Basic econometrics. ( $5^{\text {th }}$ edition). New York: McGraw Hill.

Jatuporn, C., \& Sukprasert, P. (2016). Forecasting models for rubber production and export quantity of Thailand. Khon Kaen Agriculture Journal, 44(2), 219-228.

Jatuporn, C., Sukprasert, P., Chulaphan, W., \& Sriariyawat, S. (2016). Assessing the impact of the exchange rate on major agricultural export commodities of Thailand. International Journal of Agricultural Technology, 12(6), 973-982.

Keerativibool, W. (2014). Forecasting model for the export value of Thai jasmine rice. Burapha Science Journal, 19(1), 78-90.

Kulthatpong, P., Jatuporn, C., \& Toyama, M. (2019). Forecasting the number of migrant workers in Thailand: Empirical study and discussion. St. Theresa Journal of Humanities and Social Sciences, 5(2), 1-18.

Kuo, H. I., Chen, C. C., Tseng, W. C., Ju, L. F., \& Huang, B. W. (2008). Assessing impacts of SARS and Avian Flu on international tourism demand to Asia. Tourism Management, 29(5), 917-928.

Lertsivanont, N., \& Boonserm, P. (2014). Forecasting import demand for fresh grapes from China. Journal of Business Research and Administration, 2(1), 68-85.

Lim, C., Chang, C. L., \& McAleer, M. (2009a). Forecasting h(m)otel guest nights in New Zealand. International Journal of Hospitality Management, 28(2), 228-235.

Lim, C., McAleer, M., \& Min, J. C. (2009b). ARMAX modelling of international tourism demand. Mathematics and Computers in Simulation, 79(9), 2879-2888. doi.org/10.1016/j.matcom.2008.08.010.

Makridakis, S., Wheelwright, S., \& Hyndman, R. J. (1998). Forecasting methods and applications. ( $3^{\text {rd }}$ edition). New York: John Wiley \& Sons.

Masood, M. A., Raza, I., \& Abid, S. (2018). Forecasting wheat production using time series models in Pakistan. Asian Journal of Agriculture and Rural Development, 8(2), 172-177.

Office of Agricultural Economics (2020). Thailand foreign agricultural trade statistics in 2019. Center of Agricultural Information, Office of Agricultural Economics. Bangkok: Thailand.

Office of the Permanent Secretary (2019). Import of Thailand classified by commodity. Information and Communication Technology Center with Cooperation of the Customs Department. Bangkok: Thailand. 
Promchon, P., Sukprasert, P., Jatuporn, C., Kittiwatsopon, K., \& Pattanakiat, S. (2018). Factors affecting table grape production: Introductory analysis. Siam Academic Review, )192(, 1-13.

Saengwong, S., Jatuporn, C., \& Roan, S. W. (2012). An analysis of Taiwanese livestock prices: Empirical time series approaches. Journal of Animal and Veterinary Advances, 11(23), 4340-4346. 